\title{
Cibercultura
}

\section{Conhecimento científico e participação social na cibercultura do Greenpeace Brasil}

\section{Scientific knowledge and social participation in Brazilian Greenpeace cyberculture}

\section{ELIZABETH MORAES GONÇALVES}

Professora do Programa de Pós-graduação em Comunicação da Universidade Metodista de São Paulo - UMESP.

<bethmgoncalves@terra.com.br>

\section{KATARINI MIGUEL}

Doutoranda em Comunicação Social na Universidade Metodista de São Paulo - UMESP.

<k-miguel@vol.com.br>

\section{RESUMO}

A educação para a ciência tem importância fundamental no sentido de capacitar o cidadão para a compreensão de fenômenos importantes, possibilitando a participação apropriada em questões sociais que têm influência direta na sociedade, tais como as relacionadas ao meio ambiente. Nesse sentido, buscase pensar essa problemática, apresentando os modelos de compreensão pública de ciência propostos por Lewenstein (2010) e confrontando com uma avaliação exploratória do portal e das redes sociais do Greenpeace Brasil para entender como se processa a compreensão da ciência no ambiente da cibercultura. $O$ texto sugere reflexões sobre o cenário das tecnologias que facilitam a difusão de informações, a participação, a interatividade, porém nem sempre contemplam o entendimento da ciência de forma a levar a uma participação significativa enquanto cidadão.

Palavras-chave: Comunicação; Ciência; Greenpeace; Cibercultura

\section{ABSTRACT}

The Education for science is of fundamental importance in order to enable the citizen to the understanding phenomenas and to get participation of social issues that have direct influence in society, such as those related to the environment. In this sense, we try to think this problem by presenting the models of public understanding of science proposed by Lewenstein (2010) and confronted with an exploratory evaluation of the sites and socials networking for Greenpeace Brazil to investigate how an understanding of science processes in the cyberculture. The text suggests reflections on the process technology that facilitates the dissemination of information, participation, interactivity, but not always reflected the understanding of science so as to lead to meaningful participation as citizens.

Keywords: Communication; Science; Greenpeace; Cyberculture. 

Certo que o movimento ambiental atua diretamente na divulgação de ciência para
seus públicos, produzindo informações, estudos e levantamento de dados por meio de pesquisas desenvolvidas ou pelas próprias organizações ambientalistas ou por outros órgãos e Institutos de pesquisa. Assuntos como aquecimento global, créditos de carbono, geração de energias alternativas, utilização sustentável da biodiversidade são correntes em diferentes plataformas como sites, blogs e redes de relacionamento, mediados por ONGs e instituições da área. Mas como se processa esta informação? Qual modelo de compreensão pública de Ciência e Tecnologia que predomina? O cenário virtual facilita a difusão de informações, a troca de opiniões, as formas de expressão, a participação do cidadão comum, mas em que medida este contexto é utilizado no sentido da educação para a ciência? A ciência está sendo um ator central neste cenário virtual das organizações ambientais? O entendimento da ciência é imprescindível para compreensão dos fenômenos, para intervenção social, para participação pública, mas a hipótese que se levanta é que a abordagem é reduzida, o debate acaba sendo particularizado, banalizado e, muitas vezes, até espetacularizado, e as questões emocionais e de maior visibilidade midiática ganham centralidade em detrimento da ciência propriamente dita. O portal e as ferramentas virtuais do Greenpeace Brasil ilustram essa proposição ao colocar em pauta assuntos mais catastróficos, campanhas chamativas, mobilizações pela defesa do meio ambiente focadas mais na concepção imagética e no impacto emocional, sem as devidas explicações científicas.

O texto se propõe a apresentar elementos que possam levar à reflexão sobre o conhecimento científico no panorama brasileiro e o nível de participação social, em especial no âmbito dos movimentos ambientais e suas formas de comunicação e expressão, sobretudo na internet. São apresentadas as possibilidades de compreensão de ciência, a partir dos modelos estabelecidos por Lewenstein (2010): déficit cognitivo, contextual, expertise leiga e participação pública. A teoria será confrontada com a 
avaliação exploratória no portal do Greenpeace, um forte representante da cibercultura ambiental e que traz indicativos importantes, ainda que iniciais.

\section{Conhecimento sobre ciência: princípio da participação}

A Declaração de Budapeste, fruto da Conferência Mundial sobre a Ciência para o século XXI, realizada em 1999, recomendou aos governantes atenção especial à educação científica, no sentido de desenvolver metodologias e recursos para que professores e pessoas envolvidas com essa educação possam ter acesso constante à atualização do conhecimento.

Segundo o documento da UNESCO, A ciência para o século XXI, a declaração de Budapeste enfatiza que "ter acesso contínuo à educação, desde a infância, é um direito humano, e que a educação científica é essencial ao desenvolvimento humano" (Unesco, 2003, p. 7). Portanto, o ensino de ciências torna-se relevante no ambiente comunicacional, entendendo que a apropriação do conhecimento científico contribui para a promoção da qualidade de vida, para a inserção social, diminuindo a exclusão e o preconceito.

A escola sozinha não desenvolve instrumentos para resolver os problemas do mundo, nem lhe cabe toda essa responsabilidade, porém não se pode abrir mão de tratá-la como um espaço para o crescimento e para a formação da cidadania, uma tarefa que ultrapassa os níveis dos conteúdos curriculares, ou, conforme Werthein (2003, p. 12):

Nem milagreira, nem impotente: assim é a escola. Para que ela possa exercer os seus papéis, é preciso que seja vista a partir de uma posição de equilíbrio. Entre o otimismo e o pessimismo pedagógico, situa-se o realismo. Nessa perspectiva, é possível examinar o que a escola pode fazer, na qualidade de sujeito, para influenciar a história do homem, em vez de ser apenas um reflexo da história." 
A justificativa mais comum para o ensino de ciências deficientes é o alto custo de laboratórios e experiências. Porém, ao se avaliar o retorno do aprendizado em termos das atitudes do indivíduo, que, munido dessa aprendizagem científica passa a desenvolver, por exemplo, hábitos de higiene, prevenção de doenças e cuidados com o ambiente, o investimento em educação torna-se irrelevante, investe-se na educação e economiza-se em saúde pública.

O Brasil está muito distante de atingir os objetivos dessa educação científica de qualidade, apesar de dados de 2010 da pesquisa Percepção Pública da Ciência e Tecnologia no Brasil mostrar que, comparado com os dados da mesma pesquisa em 2006, aumentou o interesse do brasileiro pela ciência. Trata-se de uma pesquisa nacional promovida pelo Ministério da Ciência e Tecnologia, com colaboração da UNESCO, com o objetivo principal de levantar dados sobre o interesse, grau de informação, atitudes, visões e conhecimento que os brasileiros (homens e mulheres com idade igual ou superior a 16 anos) têm da ciência e tecnologia. (Ministério de Ciência e Tecnologia, 2010).

Tal evolução, contudo, não se mostrou suficiente para que o posicionamento do país em pesquisa internacional fosse eficiente: o Brasil é dos últimos colocados. O Programa Internacional de Avaliação de Alunos (PISA ${ }^{1}$ ), desenvolvido pela Organização para Cooperação Econômica e Desenvolvimento $\left(\mathrm{OECD}^{2}\right)$, organização intergovernamental de países industrializados, visa a fornecer indicadores de alta qualidade de ensino. O Brasil participa dessa pesquisa, buscando conhecer as experiências internacionais existentes na área de avaliação educacional, além de comparar os resultados gerais do país com os dados dos Estados do país. Procura-se, nessa pesquisa, avaliar o preparo do aluno para a vida, os conhecimentos e habilidades para enfrentar situações no mundo do trabalho, considerando que o aprendizado deve ir além do currículo escolar.

A pesquisa do PISA/2009 foi aplicada 470 mil estudantes (20 mil deles, brasileiros), nascidos em 1993. Os Resultados apontam que o nível de educação no Brasil teve um 
crescimento bastante significativo de 2000 (primeira vez que a pesquisa foi realizada) a 2009 (última edição da pesquisa). Os únicos países que tiveram crescimento maior foram Chile e Luxemburgo. Porém, tal crescimento ainda não tira o país das últimas colocações no ranking dos 65 países que participam da pesquisa - o Brasil é o 53ํo em ciências e leitura e 57ํㅡ em matemática (atrás do Chile, Uruguai e Colômbia, por exemplo) (Ministério da educação, 2009).

Tal pesquisa aponta ainda para maior preocupação em relação ao ensino das escolas públicas, que apresentam, em relação às privadas, rendimento ainda inferior - situação que tem se perpetuado no país, na medida em que o Estado, não investe em Educação na proporção necessária.

Essa situação nos leva a repensar a proposta da educação de ciências na escola e também na educação pela mídia e pelas organizações, embora seu objetivo não seja diretamente a educação formal. Ao tratar de assuntos que envolvem a ciência, a divulgação de dados de pesquisas deveria ser eficiente, objetiva e capaz de gerar no país uma cultura capaz de fazer o brasileiro se orgulhar de sua participação social, não apenas por um melhor posicionamento nos rankings das pesquisas internacionais, mas na diferença que pode fazer na sua vida e na sua sociedade. Nesse cenário, as ONGs ambientalistas e, em especial o Greenpeace, têm grande responsabilidade ao envolver o cidadão em uma participação social de qualidade.

Vale lembrar que o conhecimento produzido pelos cientistas, pesquisadores das mais diferentes áreas, em Universidades e centros de pesquisa, deve circular para validarse. Evidentemente há um processo de difusão desse conhecimento entre os pares, porém o cidadão comum deve ter acesso a esse conhecimento no sentido de formarse para uma participação social efetiva. Estamos falando do processo de divulgação científica, que tem crescido nos últimos anos, tanto em revistas especializadas quanto em publicações mais amplas, dirigidas ao público leigo, sobretudo nos espaços virtuais 
criados a partir da expansão da internet. Sem contar com tantas outras formas de divulgação, pelos meios de comunicação, museus de ciências e muitas iniciativas de organizações governamentais e não governamentais. Porém, estamos sempre entre uma divulgação extremamente simplificada e simplista, que não dá conta de fornecer material suficiente para um conhecimento de qualidade, ou então uma linguagem hermética, de jargão científico, que, da mesma forma, não chega a atingir o público em geral.

Maria da Conceição Ruivo (2004) revela a dificuldade em definir ciência e aponta a linguagem como um fator limitante para a compreensão, uma vez que em cada domínio existem conceitos e modos de fazer específicos e reservados a determinada comunidade científica.

Naturalmente, todos estaremos de acordo em que a natureza da ciência é um tema de grande complexidade e que, ao discorrer sobre ele, corremos riscos de fazer simplificações abusivas e interpretações sujeitas a um dado viés. Mas porque não adotar, também nesta matéria, a atitude que é tradicionalmente atribuída aos cientistas, a de um distanciamento critico, que não impede, no entanto, a ação, a da partilha de pontos de vista, a da confiança nos pares?"

(Ruivo, 2004, p. 587)

A ciência, assim como suas teorias, faz parte de uma objetividade construída, resultado de leitura e representações, e está tão contaminada e condicionada psicologicamente como qualquer outra ação humana. Nesse sentido, Ruivo (2004, p. 596) 
prega a criação de uma cultura científica, para que a mesma faça parte do cotidiano, por mais que o conhecimento tenha como fim superar ou mesmo ir contra o senso comum, é importante caminhar para que a ciência possa constituir-se em cultura. Ao mesmo tempo, a autora reconhece a dificuldade da ciência "educar do alto da sua cátedra" e acredita que o núcleo duro ainda ficará restrito, e que, para estabelecer um conhecimento é preciso avançar além das linguagens, decifrando outros mapas que permitam compreensão e apreensão da ciência enquanto cidadão (Ruivo, 2004, p. 599).

O desafio está, portanto, em se criar uma cultura científica, mesmo entendendo que todo processo que envolve a pesquisa científica e divulgação dos seus resultados está suscetível aos aspectos econômicos e políticos, que tanto podem servir à sociedade quanto a interesses econômicos (Cuevas, 2008). A mesma autora lembra que, muitas vezes, o êxito ou fracasso de uma teoria científica só depende da maior ou menor habilidade de seus interlocutores provarem sua superioridade. Mas, como atribuição pública dos governos, os processos de ciência, tecnologia e inovação devem ser amplamente divulgados e disponibilizados à intervenção, o que se tornou estratégia política das gestões públicas. Com isso, os cidadãos passaram a ter mais acesso às decisões científicas, inclusive, como lembra Rothberg (2008), foram elaborados instrumentos adequados que não só facilitam como convocam à participação na formulação de políticas de ciência e tecnologia, como são os exemplos das conferências de consenso e das consultas públicas presenciais ou online. Mas, o cidadão está preparado para essa participação, ou seja, tem conhecimento suficiente para tal?

As audiências públicas online, também denominadas como consultas públicas ou chamadas para debate, fazem parte de uma política de participação e controle popular da administração pública, que vem acontecendo há pelo menos 10 anos no Brasil, normalmente, em portais governamentais, possibilitando a manifestação, 
sugestões, comentários a distância, de quaisquer interessados, sobre os temas em discussão. Assuntos como transgênicos, produção e consumo sustentável, resíduos sólidos, propostas brasileiras para a Rio+20 já foram colocados para o debate no site do Ministério do Meio Ambiente. Mas a intervenção depende do grau de conhecimento e engajamento do cidadão, o que permite afirmar que assuntos que exigem conhecimento científico, como são os casos dos citados, situam-se em um "reduto" exclusivo, poucos se manifestam e aqueles que interferem têm formação acadêmica na área, pertencem aos grupos em questão, ou seja, um debate altamente especializado que conta com pouca participação popular de fato. Os meios para participação pública e entendimento da ciência existem e são latentes com as ferramentas da internet, mas falta ainda a cultura científica e de participação.

\section{O movimento ambiental e a divulgação da ciência no contexto das TICs}

A luta ambiental remonta ao século XIX com o advento da revolução industrial. Os movimentos contraculturais, que exigiam espaços de negociação e discussão, passaram a fazer duras críticas às formas de produção econômica, que resultaram na degradação ambiental das mais diferentes formas.

As reivindicações ganharam força e visibilidade a partir de 1960, com novos atores e movimentos sociais povoando a cena política e colocando em pauta a apropriação da natureza, a defesa dos recursos naturais, as formas de consumo e os modelos de desenvolvimento econômico e social. Foi nessa época que a publicação do romance de Rachel Carlson, Silent Spring, acendeu um alarme ao descrever os efeitos dos agrotóxicos ao meio ambiente e denunciar abertamente a degradação da natureza, especificamente nos Estados Unidos, o que deu relevância e abrangência à questão ambiental. Em seguida, vieram a Conferência de Estocolmo, em 1972, a criação do 
Pnuma (Programa das Nações Unidas para o Meio Ambiente), o relatório Nosso Futuro Comum, que cunhou a expressão Desenvolvimento Sustentável, as comissões Rio92, Rio +10 e a problemática ambiental foram inseridos na agenda pública, governamental e midiática, abrindo o campo para a consolidação das ONGs (Organizações Não Governamentais) voltadas para a preservação ambiental. A primeira organização de espectro mundial foi a WWF, criada em 1961. O Greenpeace surgiu em 1971, já com uma ação de projeção internacional: uma mobilização contra o teste nuclear em uma ilha no Canadá e ganhou bases praticamente por todo o globo, presente atualmente em 40 países. O Brasil ganhou a primeira entidade ambientalista, também em 1971, a Agapan (Associação Gaúcha de Proteção ao Ambiente Natural). O Greenpeace fixou base por aqui oficialmente em 1992.

As ONGs compõem o que se denomina Terceiro Setor, considerando o primeiro o Estado e o segundo o Mercado, e ganharam relevância ao longo dos anos ao mesmo tempo em que foram colocadas em xeque, pois apesar de não governamentais, não só atuam em áreas próprias do poder público como também usufruem de verbas do governo. O conceito contemplou abordagens tradicionais de filantropia, solidariedade, caridade, ação social para caracterizar, mais especificamente a partir da década de 1990, como terceiro setor os grupos de pessoas que atuam pela promoção de interesses coletivos (Coelho, 1999).

Segundo a Abong (Associação Brasileira de Organizações não Governamentais) são cerca de 300 mil organizações no país atuando com educação, saúde, lazer, cultura e meio ambiente. É fato que as ONGs cresceram e se profissionalizaram com atividades sociais, políticas, militantes, menos centradas no indivíduo e mais nos direitos do grupo. A partir de seus próprios levantamentos, pesquisas, feitas por profissionais altamente qualificados, se observou que as organizações ambientalistas são cada vez mais produtoras de conhecimento. 
O movimento que nasceu para defender a natureza, desde sua fundação demonstrou um caráter midiático, que contribuiu com sua legitimidade social e com a difusão da causa ambiental. As ONGs tornaram-se referência e são exaustivamente procuradas como fontes de informações, formuladoras de conceitos, de novas diretrizes e pautas para a imprensa e sociedade. Avaliando a produtividade histórica dos movimentos sociais por seu impacto em valores culturais, na opinião de Castells (2000), o movimento ambiental foi o que adquiriu o maior destaque, em parte pela capacidade de se comunicar e por ter transpassado diversos setores da sociedade, atingindo plataformas políticas e empresariais. $\mathrm{O}$ autor define o ambientalismo como uma forma de comportamento coletivo que atua no discurso e na prática para corrigir formas destrutivas de relacionamento entre o homem e seu ambiente natural com concepções diversas.

A incidência das tecnologias de informação e comunicação, pós década de 1960, e a formação da sociedade em rede, coincidiram, justamente, com a ascensão do movimento ambiental, que soube se apropriar das ferramentas virtuais para difundir a causa, conseguir adeptos, lançar manifestos e divulgar informações, além de se configurar como um dos atores sociais que mais utilizam a rede virtual na contemporaneidade, abrindo novos espaços de confrontação e negociação no ciberespaço, evidenciando as divulgações científicas e as demandas de participação social e de luta pelo poder.

Vale ressaltar aqui, como enfatiza Echeverria (2008), o papel das novas tecnologias para o conhecimento da ciência, na medida em que estas produzem uma profunda revolução na forma de adquirir informação. A internet e seus aplicativos são vistos não só como tecnologias, mas como um novo espaço social, eletrônico, telemático, de capacidades e, todavia, reticular. A sociedade em rede se estabelece como metáfora da apropriação de ciência e tecnologia. 
No âmbito dessa rede tem-se a composição da cibercultura entendida por Lévy (1999) como um novo universo que alia técnicas, práticas, atitudes, modos de pensamento, de valores e manifestações que se desenvolvem no ciberespaço. Tratase de uma cultura digital propiciada pela interconexão mundial de computadores, englobando a infraestrutura material e também "o universo oceânico de informações que ela abriga, assim como os seres humanos que navegam e alimentam esse universo (Lévy, 1999, p. 17)".

Focalizando a cibercultura do Greenpeace, ela vai ao encontro da definição de Lévy (1999) na medida em que disponibiliza um terreno multi/hipermidiático, com a mesma estrutura estética e informativa nos 33 portais eletrônicos que possui, representando os 40 países onde atua - reunindo textos, fotos, vídeos, blog, redes sociais, documentos, manifestos em um mesmo espaço - trazendo temas diferenciados e que exigem explicações científicas. Um universo de informações e possibilidades.

Temas que tangenciam questões como desenvolvimento sustentável, conservação da biodiversidade e qualidade de vida despertam um interesse real e impulsionam manifestações espontâneas, devido a emergência da questão ambiental, a quantidade de sites e instituições na área, as comunidades virtuais e seus seguidores. Mas a participação pressupõe certo interesse e repertório que possibilitem manifestações seguras e apropriadas. A cibercultura ambientalista, nesse contexto, tem um papel fundamental de fornecer informações que propiciem a construção de um conhecimento capaz de levar à participação e à confrontação de pontos de vista.

Nos ambientes específicos de informação ambiental evidenciam-se não só notícias relacionadas ao tema, mas também campanhas, manifestações, petições, fóruns de debate, como é facilmente notado no portal do Greenpeace. Rothberg (2010) avalia os espaços online, no caso específico das consultas públicas, mas toma-se a liberdade de estender aqui sua avaliação à cibercultura ambiental, extrapolando os limites 
tradicionais da disseminação da informação realizada por campanhas políticas ou mesmo no âmbito do jornalismo convencional, que ora simplificam demais a ciência com técnicas de marketing, ora a colocam no âmbito do espetáculo. Mas se antes a comunicação era unidirecional e centrada nas mídias convencionais, atualmente, com as tecnologias, o fluxo tem conexões multidirecionais que permitem a participação efetiva.

Assim, faz-se necessário questionar como a cibercultura pode contribuir para o processo de compreensão pública da ciência preparando o cidadão para intervir nas políticas ambientais.

Espaços próprios de participação e engajamento como as redes sociais, colocam assuntos altamente importantes e que exigiriam conhecimento para comentários. Mas nota-se um fundo emocional muito latente nesses processos, com comentários acalorados, momentâneos, que não geram debates ou discussões, e uma adesão muito mais quantitativa às causas ambientais do que propriamente de participação.

O Facebook da instituição, que pode ser apontado como a ferramenta virtual mais utilizada e com maior grau de participação, vem superando sites e blogs como espaços de debate, o que pode ser facilmente comprovado pelos acessos. A título de exemplificação, um mesmo post, do dia 23 de novembro, que trazia ao vivo a votação das reformas do Código Florestal, enquanto na rede social obteve mais de 60 acessos e 10 comentários em apenas duas horas de postagem, no blog, que disponibilizava a votação ao vivo, não recebeu nenhum comentário. Mas a tendência é a ocorrência de comentários isolados, sem conteúdo ou propostas que permitam gerar um debate ou discutir mais cientificamente, no caso, a questão do Código Florestal, como os exemplos: "prender ladrao morro da rocinha é tarefa facil quero ver prender ladrao ai em brasilia. kkkkkkkk" (sic); "VIVA A DEMOTUCANOCRACIA RURALISTA" (sic); 
"nemhum q esta no governo referindo tdos os cargos da alta escala governamental tdos nao PRESTAM SAO SAFADOS" (sic) ${ }^{3}$.

Outra observação latente é em relação aos temas mais emotivos que recebem, de fato, mais comentários e acessos (que, no caso, podem ser verificados pela quantidade de vezes que o item foi "curtido" no Facebook), enquanto assuntos mais científicos têm poucas intervenções. O post do vazamento de óleo ocasionado pela empresa Chevron, na Bacia de Campos (RJ), dia 21 de novembro, teve quase 500 acessos, 300 compartilhamentos e 63 comentários. Mas, que não significaram uma discussão política ou científica do caso, e sim a demonstração de indignação, repulsa, descrença, insultos à empresa poluidora e questionamentos ao governo. Enquanto um post sobre o mesmo assunto, porém, anterior ao vazamento, datado de 18 de novembro, sobre a campanha Petróleo em Abrolhos não! que trouxe links para petição e informações sobre as consequências do derramamento de óleo, recebeu apenas 300 acessos e 12 comentários. Confirmando essa tendência de participações quando o assunto é atrativo, espetacular, o post que mostrava os ativistas na sede da empresa Chevron jogando óleo, gerou bem mais interesse com 40 comentários e 430 curtições. Também publicado antes do vazamento de óleo.

Na mesma linha que evidencia que, questões mais científicas não geram interesse ou mesmo o debate, está uma publicação da ONG na rede sobre o relatório do Banco Mundial, informando que $20 \%$ do que os países investem em energia suja é suficiente para criação de um fundo verde para mitigar mudanças climáticas - assunto com viés político e científico, publicado em 6 de novembro de 2011 - recebeu apenas seis comentários, sendo apenas dois diretamente relacionados ao tema, enquanto a campanha Desliga essa Motosserra! que evidencia atores globais, tem em média 20 comentários em cada post relacionado e mais 300 curtições, com o atrativo título Atenção senadores! Capitão nascimento ordena: desliga essa motosserra! A campanha tem 
ainda mais adesão no Facebook porque permite que os usuários tirem fotos com os cartazes da campanha e compartilhem na página.

\section{Os modelos de compreensão pública de ciência: entre o ideal e o real}

A percepção e compreensão da ciência pode se dar de diversas formas, Lewenstein (2010) propõe quatro modelos de compreensão pública apropriados, que podem ser confrontados no portal e ferramentas do Greenpeace. O primeiro deles é o modelo do déficit cognitivo, que consiste unicamente na tentativa de sanar as falhas de compreensão, as lacunas de conhecimento a respeito da ciência. Nesse caso, o cientista é soberano no entendimento das questões, ainda que isoladas . Cuevas (2008) alerta que essa estrutura é predominante no discurso político e educativo da contemporaneidade, e também no midiático, são modelos que buscam explicar os procedimentos e descobertas científicas de forma direta, determinista, muitas vezes, sem a contextualização ou a complexidade das situações.

Já no modelo contextual, o entendimento da ciência considera o público em específico, o contexto cultural e circunstancial dos envolvidos. Os dois primeiros casos, lembra Lewenstein (2010), são frequentemente utilizados para equiparar o entendimento público de ciência, sem ponderar questões políticas, sociais e econômicas, atuando na retórica do consenso para influenciar decisões na área.

A expertise leiga é um modelo que se constrói a partir de noções empíricas, considerando o conhecimento do outro sobre sua realidade e, nesse caso, vale ressalvar que o conhecimento tido como tradicional pode contribuir efetivamente para solução de problemas técnicos. O último e, mais apropriado dos modelos, é denominado de participação ou engajamento público, que pressupõe uma estrutura dialógica, colaborativa, utilizando para isso estratégias como conferências de consenso, júri cidadão e audiências públicas, na tentativa de democratizar a ciência e discutir os 
assuntos em todos os níveis. Seria, portanto, o modelo ideal, aquele que não oferece respostas prontas a respeito da ciência, como no caso dos exemplos anteriores, mas permite que o cidadão componha e participe das demandas científicas.

Vale integrar a esta proposta dos modelos de compreensão pública da ciência, o entendimento do discurso científico e sua probabilidade de justaposição com o discurso político, conforme Coracini (1991). A autora lembra que os dois discursos podem ser considerados subjetivos e argumentativos, além de servirem a uma série de convenções partilhadas pela comunidade interpretativa. Mas a opacidade da linguagem desses discursos consegue convencer da verdade (aparente) que enunciam.

Ambos os discursos - científico e político - são argumentativos, mas existe uma tensão no discurso político, pois, uma situação de conflito pode anular uma das partes, enquanto que no científico uma teoria não invalida necessariamente a outra. Assim, há sempre uma evolução, a formulação de hipóteses e contra-hipóteses que não podem ser deterministas. O político ainda traz consigo vocábulos carregados de pressupostos ideológicos e apelativos à uma situação, buscando construir uma perspectiva que corresponda à expectativa do que a autora ressalta como público-eleitor, o qual, no caso do movimento ambiental, pode-se pensar em adeptos e ou filiados. Esse tipo de construção é constante no movimento ambiental que busca persuadir com estratégias de linguagem bastante apelativas e dramáticas, ou mesmo publicistas, propagandística. Até porque a terminologia científica é, na maioria das vezes, incompreensível ao grande público, pois, obedece a critérios rígidos de verificação e comprovação, com uma objetividade que, muitas vezes, não alcança as finalidades de sensibilização e mobilização que pretende o movimento ambiental.

Em uma avaliação exploratória no portal do Greenpeace ${ }^{4}$, tem-se nas seções temáticas fixas o item $O$ que fazemos com temas que mereceriam explicações cientificas: Amazônia; Clima e Energia; Nuclear; Oceanos e Transgênicos e, portanto, foram 
centralizados aqui a título de ilustração. O portal disponibiliza, para aclarar os temas, textos explicativos, sempre com mapas, fotos, links para mais informações, referências ao trabalho e mobilizações encabeçadas pelo Greenpeace, ainda que com linguagem acessível, simplificada, ou reduzida, visando atingir um público mais amplo. Ao mesmo tempo em que mostra certa preocupação em oferecer dados mais científicos e oficiais, disponibilizando estudos na área.

Na seção Clima e Energia, por exemplo, há link para um relatório, Revolução energética: perspectivas para uma energia global sustentável, produzido pela própria ONG, com 98 páginas, sobre as novas fontes energéticas que podem suprir demanda por energia ${ }^{5}$. O documento traz muitas imagens, gráficos, levantamentos, informações itemizadas para explicar as questões, mas apesar de dados objetivos, utiliza de uma linguagem fácil, por vezes catastrófica, e que evidencia os piores cenários, com expressões tendenciosas que relativizam a ciência: “os danos serão irreversíveis, evitar piores impactos, tempo está se esgotando". As fotos também trazem imagens impactantes como de vazamento de óleo, derretimento de geleiras polares, poluição de veículos e queima de carvão. Na mesma linha, também é disponibilizado um relatório na seção Oceanos, resultado de pesquisa com mais de 40 especialistas, que embasou a criação da campanha do Greenpeace, com o mesmo nome. O documento em formato de Atlas: Mar, petróleo e biodiversidade - a geografia do conflito, foi lançado em $2010^{6}$. Também é um documento, a priori científico, realizado com profissionais qualificados, mas tendencioso, com linguagem espetacular que evidencia termos como "rota de colisão", "história de descaso", "diametralmente oposto"...

Este panorama permite confirmar a preocupação com a ciência. A própria organização promove e realiza estudos, levantamentos e os divulga, mas não alcança um modelo apropriado de compreensão pública da ciência ou mesmo expertise leiga, pois atua apenas para suprir o déficit cognitivo, sinalizando, em alguns momentos, 
para um modelo contextual, já que se comunica com um nicho específico de pessoas que tem acesso à internet e interesse pela questão ambiental. O discurso do Greenpeace também é muito mais político do que científico. Haja vista as expressões persuasivas, a proposta de convencer e vender uma causa. Os próprios documentos mencionados são explícitos em suas recomendações políticas. Essa premissa ainda é corroborada em uma breve análise das próprias campanhas da organização.

Assuntos polêmicos que também exigem caráter científico são tratados com irreverência, humor e que podem ter como finalidade atrair públicos distintos, mas minimizam questões científicas e políticas mais sérias. As duas petições/campanhas ciberativista em andamento no momento da produção deste trabalho (novembro e dezembro de 2011) Em defesa das florestas, abaixo assinado contra as alterações do Código Florestal, e Petróleo em Abrolhos não! que solicita a moratória de 20 anos na exploração de gás e petróleo na região de Abrolhos, são denominadas nos sites e redes sociais como Desliga essa motoserra! e Deixa as baleias namorarem!. A linguagem é fácil, atrativa, desperta o interesse, mas pouco científica. A poluição dos mares e a perda da biodiversidade, por exemplo, são restringidas a deixar as baleias namorarem, o que pode minimizar debates mais importantes, haja vista as poucas ou insignificantes manifestações na rede social quando o assunto exige determinado conhecimento e interesse.

O rigor científico e a proposta de participação pública da ciência, podem estar sendo deixados de lado para dar espaço a uma proposta espetacularizada, tendenciosa, que pode gerar mais interesse dos usuários, porém foge da objetividade científica.

\section{Algumas considerações}

Esta avaliação, ainda que exploratória e preliminar, foi suficiente para averiguar que o movimento ambiental, no âmbito da cibercultura, ainda não atua sistematicamente 
para uma compreensão pública da ciência, apesar dos assuntos serem propícios e possuírem à disposição ferramentas para abranger e dar teor aprofundado, participativo e, acima de tudo, engajado para as questões. Observou-se no conteúdo produzido pelo Greenpeace, um tratamento isolado, fragmentado das questões, com vistas ao espetáculo, ainda que produzam e disponibilizem documentos formais, elaborados por pesquisadores da área e coloquem em pauta questões importantes, pouco contribuem para entendimento da ciência.

Optam, sim, por um discurso político ou mesmo propagandístico, comprovável, por exemplo, pela escolha das palavras e pelo tom persuasivo, em detrimento do entendimento da ciência e acabam por atuar apenas com um modelo de déficit cognitivo, por vezes contextual, mas que não chega a expertise leiga, pois não considera outros conhecimentos, e, apesar das ferramentas disponibilizadas, ainda não alcançou o ideal de participação e engajamento público conforme propõe Lewestein (2010).

Mas é notável no espaço da ONG a disponibilização de informações, as pesquisas realizadas, a busca constante por participação e interação do usuário, estimulada, através de fóruns, link das redes sociais, ampliando de forma imensurável o alcance e a importância da causa. A ONG vem conquistando adeptos e fazendo alertas, além de sinalizar para um modelo participativo, que, no entanto, acaba por restringir a participação ao encaminhamento de mensagens, assinatura de petições e comentários, previamente filtrados pelo moderador, sem um fio condutor ou animador do debate.

No que se refere à apropriação das tecnologias, o movimento ambiental, como se evidencia, sabe utilizar e aproveitar as vantagens do espaço virtual - velocidade, autonomia, instantaneidade, quantidade, mas não efetiva, como orienta Cuevas (2008), um modelo ideal participativo que permita que os usuários tenham realmente um papel no apontamento de resolução de problemas científicos, ligados à área ambiental. 
Nesse sentido, o desafio da cibercultura ambiental deve ser justamente converter informações sobre assuntos complexos científicos em uma linguagem acessível para os cidadãos, de forma contextualizada, propiciando e estimulando a participação e atuando no incremento de um modelo de compreensão público tão necessário para o entendimento da ciência e do estabelecimento de uma cultura científica.

O acompanhamento do portal e das redes sociais do Greenpeace Brasil propiciou uma avaliação de que a participação do público é maior quando se trata de assuntos de caráter emotivo do que nas temáticas que exigem um conhecimento político e científico mais apurado, o que indicia a falta de preparo desse internauta para atuar efetivamente nas questões que o afetam diretamente. Nesse sentido, defende-se a posição de que esses espaços virtuais poderiam ser utilizados de forma mais efetiva para uma educação científica, embora essa não seja sua proposta primeira, mas poderia ser a condição para uma interação de qualidade.

\section{REFERÊNCIAS}

ASSOCIAÇÃO BRASILEIRA DE ONGS. ONGs no Brasil. Disponível em: <www.abong.org.br>. Acesso em: 02 dez. 2012.

CASTELLS, Manuel. O poder da identidade. São Paulo: Paz e Terra, 2000.

COELHO, Simone. Terceiro Setor: um estudo comparado entre Brasil e Estados Unidos. São Paulo: Senac, 2000. CORACINI, Maria José. Um fazer persuasivo: o discurso subjetivo da ciência. São Paulo: Educ, Campinas, SP: Pontes, 1991.

CUEVAS, Ana. Conocimiento científico, ciudadanía y democracia. Revista Iberoamericana de Ciencia, Tecnología y Sociedad-CTS, v. 4, n. 10, pp. 67-83, 2008.

ECHEVERRÍA, Javier. Apropiación social de las tecnologías de la información y La comunicación. Revista Iberoamericana de Ciencia, Tecnología y Sociedad - CTS, v. 4, n. 10, pp. 171-182, 2008.

GREENPEACE BRASIL. Home-page oficial. Disponível em: <http://www.greenpeace.org/brasil>. Acesso em: 15 dez. 2011.

LÉVY, Pierre. Cibercultura. São Paulo: Editora 34, 1999. 
LEWENSTEIN, Bruce V. Models of public communication of science and technology. Disponível em: <http://www. dgdc.unam.mx/Assets/pdfs/sem_feb04.pdf>. Acesso em: 02 dez. 2011.

MINISTÉRIO da Educação. INEP. Resultados preliminares PISA/2009. Disponível em: <http://www.abruc.org. br/sites/500/516/00001872.pdf>. Acesso em: 15 mar. 2011.

MINISTÉRIO de Ciência e Tecnologia. Percepção pública da Ciência e Tecnologia no Brasil - resultados da enquete de 2010. Disponível em: <http://www.fiocruz.br/museudavida_novo/media/enquete2010.pdf>. Acesso em: 15 mar. 2011.

ROTHBERG, Danilo. Contribuições a uma teoria da democracia digital como suporte à formulação de políticas públicas. Revista Iberoamericana de Ciencia, Tecnología y Sociedad .Disponível em: <http://www.revistacts.net/ files/Volumen\%205\%20\%20N\%C3\%BAmero\%2014/Rothberg_edit.pdf>. Acesso em: 12 dez. 2011.

RUIVO, Maria da Conceição. A ciência tal qual se faz ou tal qual se diz? In: SANTOS, Boa Ventura de Sousa (Org.). Conhecimento prudente para uma vida decente - um discurso sobre as ciências revisitado. São Paulo: Cortez, 2004.

UNESCO. A ciência para o século XXI - uma visão e uma base de ação- Budapeste e Santo Domingo, 2003. Disponível em: <http://unesdoc.unesco.org/images/0013/001315/131550por.pdf>. Acesso em: 20 mar. 2011.

WERTHEIN, Jorge. Crenças e esperanças: avanços e desafios da UNESCO no Brasil, 2003. Disponível em: <http://unesdoc.unesco.org/images/0013/001329/132969por.pdf>. Acesso em: 20 mar. 2011.

\section{NOTAS}

1 Em inglês: Program for International Student Assessment.

2 Em inglês: Organization for Economic Cooperation and Development.

3 Transcrição literal a partir da página da Instituição na rede de relacionamento facebook.

$4<$ http://www.greenpeace.org/brasil/pt/>.

5 <http://www.greenpeace.org/brasil/Global/brasil/report/2007/6/greenpeacebr_070202_energia_revolucao_ energetica_brasil_port_v1.pdf $>$.

6 <http://www.greenpeace.org/brasil/pt/Documentos/Mar-petroleo-e-biodiversidade/>. 